\title{
STATIC BALANCE IN OLDER ADULTS WITH CHRONIC OBSTRUCTIVE PULMONARY DISEASE UNDERGOING PULMONARY REHABILITATION
}

\author{
Equilíbrio estático em idosos com doença pulmonar \\ obstrutiva crônica participantes de reabilitação pulmonar
}

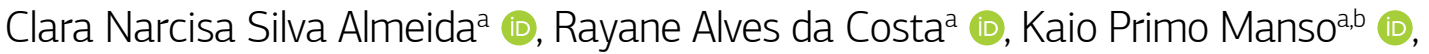

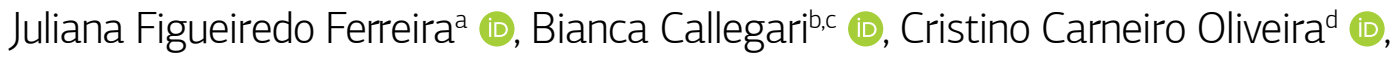 \\ Laura Maria Tomazi Neves ${ }^{\mathrm{ce} e}$ (1)
}

OBJECTIVE: To compare balance between older adults with and without chronic obstructive pulmonary disease (COPD) in tasks involving proprioceptive changes and respiratory muscle load, and to investigate the association between balance, functional capacity, and peripheral and respiratory muscle strength. METHODS: Fourteen older adults with COPD undergoing pulmonary rehabilitation and nine older adults without pulmonary disease were evaluated for static balance on a force platform under four conditions: eyes open, eyes closed, eyes closed on foam, and eyes open with respiratory overload. Differences between groups, among conditions and group/condition interactions, were tested using two-way ANOVA. Associations were explored using Pearson's

$\vdash \quad$ correlation coefficient. RESULTS: No differences in the posturographic variables were found in the group/condition interactions $\varangle \quad(p \geq 0.23)$. The COPD group exhibited greater total displacement $(F=8.79, p=0.003)$, mediolateral sway $(F=4.01, p=0.04)$ and anteroposterior velocity $(F=4.28, p=0.04)$ in the group effect analysis. Significant differences were found between eyes closed on foam and other conditions for all posturographic variables: anteroposterior sway ( $F=13.39$ ), mediolateral sway $(F=28.58)$, total displacement $(F=59.4)$, area $(F=37.68)$, anteroposterior velocity $(F=26.42)$, and mediolateral velocity $(F=33.29)$, in the condition effect analysis ( $<0.001$, post-hoc). In the COPD group, significant correlations were found between the Glittre-ADL test, anteroposterior sway $(r=0.68, p=0.01)$, and anteroposterior velocity $(r=0.67, p=0.009)$; the $6 \mathrm{MWT}$ was also correlated with anteroposterior velocity $(r=0.59, p=0.03)$. CONCLUSION: Older adults with COPD present balance deficits compared to healthy individuals. The unstable surface caused greater postural instability compared to other conditions in both groups. Impaired balance was associated with reduced physical function and exercise capacity.

KEYWORDS: chronic obstructive pulmonary disease; aged; postural balance; proprioception; respiratory muscles.

aSchool of Physical Therapy and Occupational Therapy, Institute of Health Sciences, Universidade Federal do Pará - Belém (PA), Brazil. 'Human Motricity Laboratory, Institute of Health Sciences, Universidade Federal do Pará - Belém (PA), Brazil.

'Graduate Program in Movement Science, Universidade Federal do Pará - Belém (PA), Brazil.

dDepartment of Physical Therapy, Universidade Federal de Juiz de Fora - Governador Valadares Campus (MG), Brazil.

ejoão de Barros Barreto University Hospital, Universidade Federal do Pará - Belém (PA), Brazil.

Corresponding data

Clara Narcisa Silva Almeida. Faculdade de Fisioterapia e Terapia Ocupacional, Universidade Federal do Pará. Rua Augusto Corrêa, 1 - Guamá CEP: 68440-000 - Belém (PA), Brazil. E-mail: claranarcisa.sa@gmail.com

Received on: 12/20/2019. Accepted on: 02/26/2020

DOI: 10.5327/Z2447-212320201900091

(C) 2020 Sociedade Brasileira de Geriatria e Gerontologia This is an open access article distributed under the terms of the Creative Commons license. 
OBJETIVO: Comparar o equilíbrio entre idosos com e sem doença pulmonar obstrutiva crônica (DPOC) em tarefas envolvendo alterações proprioceptiva e sobrecarga muscular respiratória além de investigar a associação entre equilíbrio, capacidade funcional e força muscular respiratória e periférica. METODOLOGIA: Quatorze idosos com DPOC participantes de reabilitação pulmonar e nove idosos sem doença pulmonar tiveram seu equilíbrio estático avaliado em uma plataforma de força em quatro condições: olhos abertos, olhos fechados, olhos fechados com espuma e olhos abertos com sobrecarga respiratória. As diferenças entre os grupos, condições e interações grupo/condição foram testadas utilizando a ANOVA bidirecional. As associações foram testadas utilizando o coeficiente de correlação de Pearson. RESULTADOS: Não foram observadas diferenças nas variáveis posturográficas nas interações grupo/condição $(\mathrm{p} \geq 0,23)$. O grupo com DPOC apresentou maior deslocamento total $(F=8,79$, $p=0,003)$, oscilação médio-lateral $(F=4,01, p=0,04)$ e velocidade anteroposterior $(F=4,28, p=0,04)$ na análise do efeito grupo. Foram encontradas diferenças significativas entre a condição de olhos fechados com espuma e as demais condições em todas as variáveis posturográficas: oscilação anteroposterior ( $F=13,39)$ e médio-lateral $(F=28,58)$, deslocamento total $(F=59,4)$, área $(F=37,68)$, velocidade anteroposterior $(F=26,42)$ e médio-lateral $(F=33,29)$, na análise do efeito condição $(p<0,001$, post-hoc). No grupo DPOC, foram observadas correlações significativas entre o teste Glittre-AVD, oscilação anteroposterior $(r=0,68, p=0,01)$ e velocidade anteroposterior $(r=0,67, p=0,009)$; o TC6m também foi correlacionado com a velocidade anteroposterior ( $r=-0,59, p=0,03$ ). CONCLUSÃO: Os idosos com DPOC apresentaram déficits de equilíbrio em relação aos indivíduos saudáveis. A superfície instável provocou maior instabilidade postural em comparação às outras condições em ambos os grupos. O equilíbrio prejudicado está associado ao desempenho funcional reduzido e à baixa capacidade de exercício. PALAVRAS-CHAVE: doença pulmonar obstrutiva crônica; idoso; equilíbrio postural; propriocepção; músculos respiratórios.

\section{INTRODUCTION}

Chronic obstructive pulmonary disease (COPD) is a preventable and treatable condition characterized by respiratory symptoms and persistent airflow limitation caused by significant exposure to harmful particles or gases. ${ }^{1}$ Besides respiratory changes, COPD leads to systemic changes, such as peripheral muscle dysfunction as well as reductions in functional mobility and exercise capacity. ${ }^{2}$ Studies demonstrated that individuals with COPD have altered postural balance, which may increase their risk of falls. ${ }^{3-5}$ The possible causes of altered postural balance in this population are peripheral muscle weakness, low level of physical activity, reduced mobility, and changes in respiratory mechanics. ${ }^{3,4}$

The capacity to generate an adequate balance reaction is determined not only by the motor response but also by the regulation of proprioceptive stimuli. ${ }^{6}$ Moreover, due to the compromised respiratory muscle mechanics, compensatory responses to balance related to the activity of the diaphragm and muscles of the trunk are impaired in COPD, which may lead to greater dependence on proprioceptive signals from the ankle and a reduction in postural stability. ${ }^{7}$ Although studies have revealed the influence of peripheral proprioceptive components and increased respiratory muscle load on postural balance in COPD, ${ }^{7,8}$ these aspects have not been investigated in individuals participating in a conventional pulmonary rehabilitation program. Pulmonary rehabilitation is recognized as a core component of the management of individuals with chronic respiratory disease, which includes exercise training, education and behavioral changes, promoting symptom improvement, exercise tolerance, and quality of life. ${ }^{9}$

The primary aim of the present study was to investigate static balance in individuals with COPD participating in pulmonary rehabilitation in two situations - submitted to external perturbation on an unstable surface and increased respiratory load. The results were compared to older adults without pulmonary disease matched for age, sex, and physical activity level. The secondary objective was to investigate possible factors associated with postural balance, such as functional capacity, peripheral muscle strength, and respiratory muscle strength.

\section{METHODS}

\section{Study design}

A cross-sectional study was conducted analyzing static balance in older adults with COPD participating in a pulmonary rehabilitation program compared to physically active individuals without pulmonary disease. This study received approval from the Human Research Ethics Committee of the Hospital Universitário João de Barros Barreto (certificate number: 1.747.881/2016). All participants signed the informed consent prior to participation. The Strengthening 
the Reporting of Observational Studies in Epidemiology (STROBE) statement was followed. ${ }^{10}$

\section{Participants}

The COPD group was recruited from the pulmonary rehabilitation program of the Hospital Universitário João de Barros Barreto in the city of Belém, state of Pará, Brazil. The inclusion criteria were: age $\geq 60$ years; diagnosis of moderate to very severe COPD based on the Global Initiative for Chronic Obstructive Lung Disease ${ }^{1}$ (forced expiratory volume in one second / forced vital capacity $\left[\mathrm{FEV}_{1} / \mathrm{FVC}\right]$ $<0.7$ after use of a bronchodilator and $\mathrm{FEV}_{1}<80 \%$ ); having participated in a pulmonary rehabilitation program for at least 6 months; clinical stability with no exacerbation in the previous 90 days; and ability to understand the study procedures instructions. Pulmonary rehabilitation involved 50-minute sessions of stretching, aerobic exercise, and strengthening exercises twice per week. ${ }^{9}$ For adequate matching to the participants with COPD in the pulmonary rehabilitation program, we recruited age-matched, community-dwelling older adults without pulmonary disease who participated in a community-based physical activity program for at least 6 months. The community-based program involved 40-minute sessions of aerobics and strengthening exercises twice per week and an additional 40-minute session of stretching exercise once per week. The exclusion criteria for both groups were comorbidities that could exert a direct influence on balance or safety during the execution of the proposed procedures, including auditory, visual and vestibular disorders, cognitive impairment, neurological or musculoskeletal conditions that limit mobility, and signs of hemodynamic instability.

\section{Procedures}

Data collection occurred between August 2016 and April 2017. The evaluation was performed in three sessions, with the assessments of peripheral and respiratory muscle strength, posturography, and functional capacity. The evaluations were always conducted in the same order for all participants at the Human Motricity Laboratory of the Universidade Federal do Pará and the Hospital Universitário João de Barros Barreto.

\section{Instruments}

\section{Peripheral muscle strength}

Peripheral muscle strength was measured using the handgrip dynamometer on the dominant arm (Saehan Hydraulic Hand Dynamometer, Model Sh5001, Korea). ${ }^{11}$ Peak handgrip strength was measured on the dominant upper limb with the elbow flexed at $90^{\circ}$ and the forearm in the neutral position.
The highest value of the three trials with less than $10 \%$ of the variation was used for analysis. Handgrip dynamometry has good test-retest reliability for isometric strength in individuals with COPD. ${ }^{11}$

\section{Respiratory assessment}

Spirometry was performed following the guidelines of the Brazilian Society of Pneumology and Phthisiology. ${ }^{12}$ Respiratory muscle strength was evaluated following Brazilian guidelines for the measurement of maximal static respiratory pressures ${ }^{13}$ using an analog pressure meter with a 2-mm orifice and nasal clip, considering the values observed in the first second after the peak pressure. Predicted values were established based on the reference equation for the Brazilian population. ${ }^{14}$ The modified Medical Research Council (mMRC) ${ }^{15}$ scale was used to assess dyspnea.

\section{Posturography}

Posturography was used to evaluate static balance in the standing position (BIOMEC400, EMG System do Brasil LTDA., SP, Brazil). ${ }^{16}$ Participants were evaluated under four conditions: eyes open (EO), eyes closed (EC), eyes closed on foam rubber surface (ECF), and eyes open with increased respiratory overload (RO) (Figure 1). The dimensions of the foam rubber were $60 \times 60 \times 10 \mathrm{~cm}$ in thickness. For the $\mathrm{RO}$ condition, participants breathed through a respiratory muscle training device (POWERbreath ${ }^{\circledR}$ classic, United Kingdom) with a nasal clip at $80 \%$ of maximum inspiratory pressure. An adjustable strap around the head was used to maintain the mouthpiece of the device fixed to the mouth. Displacement of the center of pressure was recorded for 60 seconds under each condition, with a 30 -second rest interval between evaluations. The first 10 seconds were not considered for analysis. The following variables were determined under each condition: total displacement area (total distance traveled on the support surface); standard deviation (mean absolute displacement); and velocity (distribution of displacement over time). Standard deviation and velocity were analyzed in the anteroposterior (AP) and mediolateral (ML) directions. Increased values for each of these variables suggest poor postural balance. ${ }^{17}$ Posturography is the gold standard for the measurement of static balance and has excellent test-retest reliability ${ }^{18}$ as well as predictive validity for falls in older adults. ${ }^{19}$

\section{Functional capacity assessment}

The 6-Minute Walk Test (6MWT) was used to evaluate exercise capacity following the guidelines of the European Respiratory Society/American Thoracic Society. ${ }^{20}$ 
Participants were instructed by 2 experienced researchers to walk as fast as possible without running for 6 minutes along a $30-\mathrm{m}$ track in a flat corridor with the ends of the track marked by cones. Standardized phrases of encouragement were given each minute. Peripheral oxygen saturation, heart rate and perceived shortness of breath (Borg scale) were monitored from minute 1 before the onset of the test to the 4th minute after the test. The total distance traveled was recorded and the better performance of two trials was used for analysis. The 6MWT is a valid, reliable tool for assessing exercise capacity for individuals with COPD ${ }^{21}$ The reference equation for the Brazilian population was used as the predicted value..$^{22}$

The Glittre-Activity of Daily Living test (Glittre-ADL) was used for the assessment of performance on activities of daily living and was administered as described by Skumlien et al. ${ }^{23}$ The test begins in the sitting position. The participant is instructed to stand up from a chair wearing a backpack with a weight ( $2.5 \mathrm{~kg}$ for women and $5 \mathrm{~kg}$ for men) and walk along a 10 -meter track. The participant goes over three steps placed in the middle of the track and continues walking until reaching shelves located at the end of the track. Three 1-kg objects have to be moved, one at a time from the top shelf (scapula height) to the bottom shelf (hip height) and then to the ground. The three objects are moved back to the bottom shelf and then to the top shelf. The participant walks back along the track over the steps and continues to the chair, where he/she sits down again. The test is finished after the participant has run the course five times. The total time needed to complete the entire test is recorded. The Glittre-ADL test is valid ${ }^{23}$ for the population with COPD. The reference equation proposed for this test $(1.558+(0.018$ $\times$ body mass index $)+(0.016 \times$ age $[$ years] $))$ was used to calculate the predicted value. ${ }^{24}$

\section{Statistical analysis}

Sample size was calculated assuming a $95 \%$ power and considering the baseline standard deviation of area $\left(\mathrm{cm}^{2}\right)$ measured in both groups under the ECF condition, the required sample was nine patients per group. The confidence interval was set at $95 \%$ and significance level at $5 \%$. A convenience sample was used due to the risk of sample loss. The Shapiro-Wilk test was used to determine the distribution of the data. The Matlab 7.1 (The MathWorks ${ }^{\circledR}$, Inc. Natick, MA, USA) was used for the analysis of the posturographic data. The unpaired t-test and Fisher's exact test were used for the inter-group comparisons of continuous and categorical variables, respectively. Two-way analysis of variance (ANOVA) was used to investigate possible differences in the group factor (COPD and without COPD) and

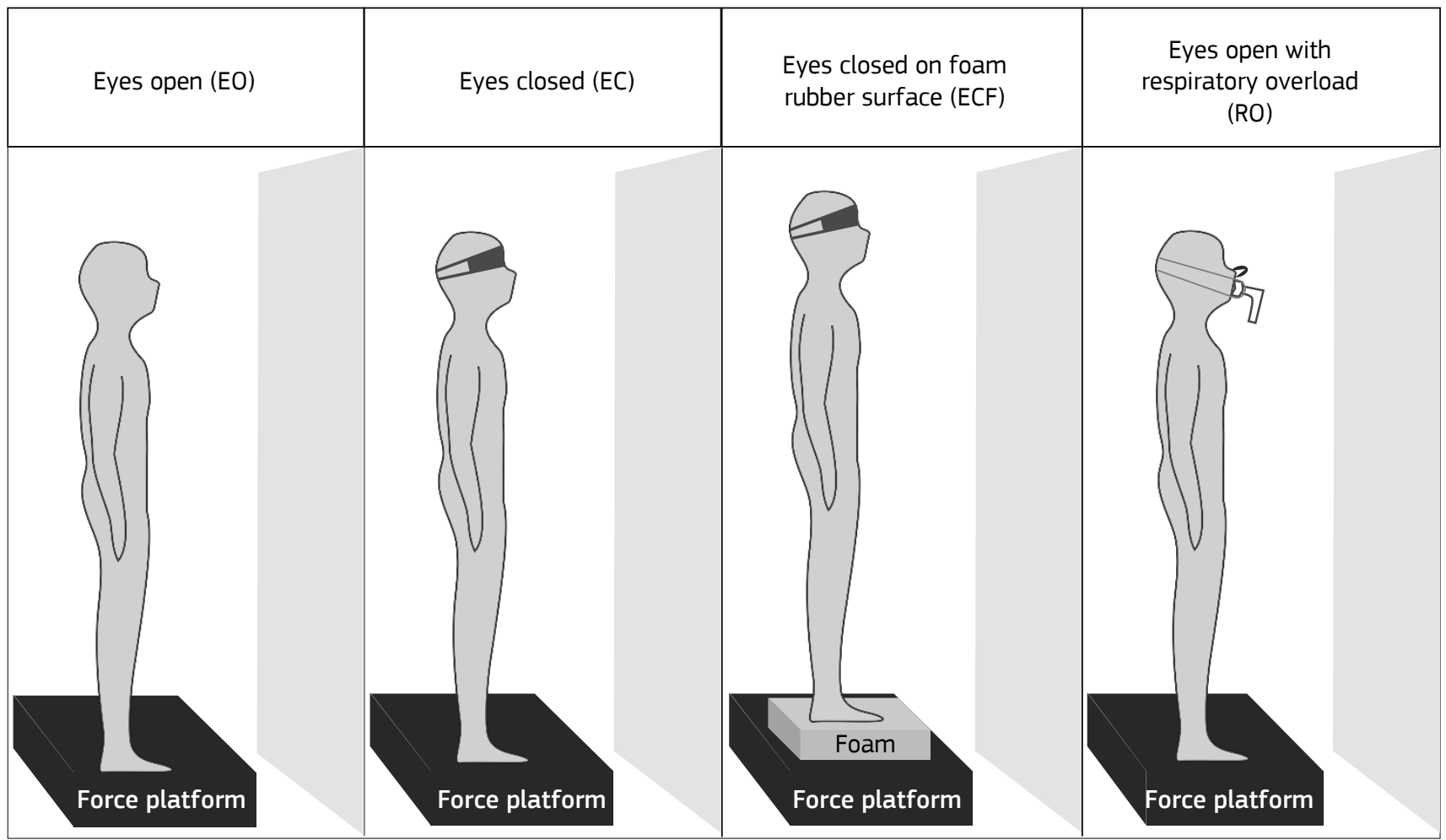

Figure 1 Conditions evaluated on force platform. 
condition factor during the static balance evaluations (EO, $\mathrm{EC}, \mathrm{ECF}$ and $\mathrm{RO}$ ). The interaction between the group and condition factors was first analyzed in a combined manner. In the absence of a significant interaction, the group and condition factors were analyzed separately. When the p-value was $\leq 0.05$ in the isolated analysis, Tukey's post-hoc test was used to determine which balance tasks differed significantly from the other tasks. Pearson's correlation coefficients were calculated to investigate possible correlations between postural balance and functional capacity, peripheral muscle strength and respiratory muscle strength. The $\mathrm{R}$ software version 3.5.1 (The R Foundation for Statistical Computing, Austria) was used for the analyses and $p \leq 0.05$ was considered indicative of statistical significance. Microsoft Office Excel $^{\circledR} 2010$ (Microsoft Corporation, USA) was used for graphs.

\section{RESULTS}

Twenty-three individuals participated in the study. One group consisted of 14 individuals with moderate to very severe COPD, and the second group of nine older adults individuals without COPD. Older adults in the COPD group have participated in the pulmonary rehabilitation program for a mean of $15(\mathrm{SD}, 8)$ months.

The demographic, clinical characteristics, functional capacity, peripheral muscle strength, or respiratory muscle strength presented with no differences between groups (Table 1). The mean inspiratory load used on the RO static balance condition was $59 \mathrm{cmH}_{2} \mathrm{O}$ in the $\mathrm{COPD}$ and $45.5 \mathrm{cmH}_{2} \mathrm{O}$ in the group without COPD.

Table 2 displays the results of the posturographic analysis. In the combined analysis, no significant differences were found for the group-condition interaction regarding the balance variables $(p \geq 0.23)$. In the isolated inter-group analysis, the COPD group exhibited greater total displacement $(\mathrm{F}=8.79, \mathrm{p}=0.003)$, greater standard deviation in the ML direction $(\mathrm{F}=4.01, \mathrm{p}=0.04)$ and slower AP velocity $(\mathrm{F}=4.28, \mathrm{p}=0.04)$ compared to the group without COPD. In the isolated inter-condition analyses, significant differences were found between the ECF and other conditions $(\mathrm{p}<0.001$, post-hoc) (area: $\mathrm{F}=37.68, \mathrm{p}<0.001$; total displacement: $\mathrm{F}=59.4, \mathrm{p}<0.001 ; \mathrm{AP}$ standard deviation: $\mathrm{F}=13.39$, $\mathrm{p}<0.001 ; \mathrm{ML}$ standard deviation: $\mathrm{F}=28.58, \mathrm{p}<0.001$; AP velocity: $\mathrm{F}=26.42, \mathrm{p}<0.001$; and $\mathrm{ML}$ velocity: $\mathrm{F}=33.29$, $\mathrm{p}<0.001$ ).

Table 3 displays the results of the correlation analysis between the posturography variables during the ECF condition, functional capacity, peripheral, and respiratory muscle strength. In the COPD group, a positive correlation was
Table 1 Demographic, clinical characteristics, functional capacity, peripheral muscle strength and respiratory muscle strength in older adults with and without chronic obstructive pulmonary disease (COPD).

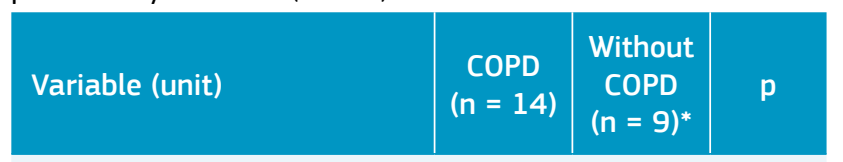

Demographic and clinical

\begin{tabular}{|c|c|c|c|}
\hline Age (years) & $69 \pm 8$ & $70 \pm 4$ & 0.75 \\
\hline Male sex & $13(93)$ & $6(67)$ & 0.26 \\
\hline BMI $\left(\mathrm{kg} / \mathrm{m}^{2}\right)$ & $24 \pm 3$ & $26 \pm 5$ & 0.19 \\
\hline \multicolumn{4}{|c|}{ GOLD classification } \\
\hline Moderate & $2(14)$ & \multirow{3}{*}{$N / E$} & \multirow{3}{*}{-} \\
\hline Severe & $8(57)$ & & \\
\hline Very severe & $4(29)$ & & \\
\hline \multicolumn{4}{|l|}{ mMRC } \\
\hline Grade 1 & $6(43)$ & \multirow{3}{*}{$\mathrm{N} / \mathrm{E}$} & \multirow{3}{*}{ - } \\
\hline Grade 2 & $2(14)$ & & \\
\hline Grade 3 & $6(43)$ & & \\
\hline
\end{tabular}

Functional capacity

\begin{tabular}{l|c|c|c}
\hline 6MWT $(\mathrm{m})$ & $440 \pm 75$ & $453 \pm 66$ & 0.90 \\
\hline 6MWT (\% predicted) & $80 \pm 13$ & $85 \pm 11$ & 0.44 \\
\hline Glittre-ADL test (min) & $5.2 \pm 1.8$ & $4.2 \pm 0.6$ & 0.23 \\
\hline $\begin{array}{l}\text { Glittre-ADL test (\% } \\
\text { predicted) }\end{array}$ & $65 \pm 19$ & $76 \pm 9$ & 0.17 \\
\hline
\end{tabular}

Peripheral muscle strength

\begin{tabular}{l|c|c|c}
\hline \multicolumn{1}{|l|}{ DUL dynamometry (kgf) } & $28 \pm 7$ & $27 \pm 7$ & 0.50 \\
\hline Respiratory muscle & $74 \pm 26$ & $57 \pm 29$ & 0.17 \\
\hline MIP $\left(\mathrm{cmH}_{2} \mathrm{O}\right)$ & $57 \pm 30$ & $59 \pm 29$ & 0.22 \\
\hline MIP (\% predicted) & $75 \pm 25$ & $65 \pm 27$ & 0.75 \\
\hline MEP $\left(\mathrm{cmH}_{2} \mathrm{O}\right)$ & $80 \pm 28$ & $72 \pm 25$ & 0.91 \\
\hline MEP $(\%$ predicted) &
\end{tabular}

BMI: body mass index; GOLD: Global Initiative for Chronic Obstructive Lung Disease (moderate: FEV $=50$ to 80\%; severe: FEV 30 to 50\%; very severe: $\left.\mathrm{FEV}_{1}<30 \%\right)$; mMRC: modified Medical Research Council; N/E: not evaluated; 6MWT: SixMinute Walk Test; ADL: activity of daily living; DUL: dominant upper limb; MIP: maximum inspiratory pressure; MEP: maximum expiratory pressure; *missing data for Glittre-ADL test $(n=8)$ and dynamometry $(n=6)$; data expressed as mean \pm standard deviation or $\mathrm{n}(\%)$. 
Table 2 Differences among groups, conditions and group/condition interactions for posturographic variables.

\begin{tabular}{|c|c|c|c|c|c|c|}
\hline \multirow[b]{2}{*}{ Variable } & \multicolumn{2}{|c|}{ Group } & \multicolumn{3}{|c|}{ Two-way ANOVA, p } & \multirow{2}{*}{$\begin{array}{c}\text { Post-hoc } \\
\text { (condition) p }\end{array}$} \\
\hline & $\begin{array}{c}\text { COPD } \\
(n=14)\end{array}$ & $\begin{array}{l}\text { Without COPD } \\
\qquad(\mathrm{n}=9)\end{array}$ & Group effect & Condition effect & $\begin{array}{l}\text { Interaction } \\
\text { effect }\end{array}$ & \\
\hline
\end{tabular}

Area $\left(\mathrm{cm}^{2}\right)$

\begin{tabular}{c|c|c|c|c|c|}
\hline EO & $3.9 \pm 2.3$ & $3.3 \pm 1.5$ & & & \\
\cline { 1 - 2 } EC & $3.8 \pm 1.9$ & $2.6 \pm 1.5$ & \multirow{2}{*}{0.08} & $<0.001^{*}$ & $0.61<0.001^{*}$ \\
\cline { 1 - 2 } ECF & $13 \pm 5.2$ & $10 \pm 7.4$ & & & \\
\cline { 1 - 2 } RO & $2.9 \pm 0.83$ & $2.6 \pm 1.1$ & &
\end{tabular}

Total displacement $(\mathrm{cm})$

\begin{tabular}{c|c|c|c|c|c|c}
\hline EO & $108 \pm 22$ & $97 \pm 14$ & & \\
\cline { 1 - 2 } EC & $122 \pm 25$ & $107 \pm 22$ & $0.003^{*}$ & $<0.001^{*}$ & 0.23 & $<0.001^{*}$ \\
\cline { 1 - 3 } ECF & $225 \pm 36$ & $180 \pm 73$ & & & \\
\hline RO & $107 \pm 17$ & $96 \pm 17$ & & \\
\hline
\end{tabular}

AP standard deviation $(\mathrm{cm})$

\begin{tabular}{|c|c|c|c|c|c|c|}
\hline EO & $0.44 \pm 0.16$ & $0.38 \pm 0.18$ & \multirow{4}{*}{0.26} & \multirow{4}{*}{$<0.001^{*}$} & \multirow{4}{*}{0.92} & \multirow{4}{*}{$<0.001^{*}$} \\
\hline EC & $0.39 \pm 0.19$ & $0.34 \pm 0.22$ & & & & \\
\hline ECF & $0.75 \pm 0.30$ & $0.65 \pm 0.27$ & & & & \\
\hline RO & $0.37 \pm 0.26$ & $0.36 \pm 0.17$ & & & & \\
\hline
\end{tabular}

ML standard deviation (cm)

\begin{tabular}{|c|c|c|c|c|c|c|}
\hline EO & $0.52 \pm 0.20$ & $0.49 \pm 0.10$ & \multirow{4}{*}{$0.04^{*}$} & \multirow{4}{*}{$<0.001^{*}$} & \multirow{4}{*}{0.84} & \multirow{4}{*}{$<0.001^{*}$} \\
\hline EC & $0.54 \pm 0.17$ & $0.44 \pm 0.11$ & & & & \\
\hline ECF & $0.94 \pm 0.15$ & $0.84 \pm 0.31$ & & & & \\
\hline RO & $0.53 \pm 0.16$ & $0.41 \pm 0.14$ & & & & \\
\hline
\end{tabular}

AP velocity $(\mathrm{cm} / \mathrm{s})$

\begin{tabular}{|c|c|c|c|c|c|c|}
\hline EO & $1.2 \pm 0.26$ & $1.0 \pm 0.17$ & \multirow{4}{*}{$0.04^{*}$} & \multirow{4}{*}{$<0.001^{*}$} & \multirow{4}{*}{0.81} & \multirow{4}{*}{$<0.001^{*}$} \\
\hline EC & $1.3 \pm 0.40$ & $1.1 \pm 0.31$ & & & & \\
\hline ECF & $2.1 \pm 0.61$ & $1.07 \pm 0.47$ & & & & \\
\hline RO & $1.1 \pm 0.25$ & $0.99 \pm 0.25$ & & & & \\
\hline
\end{tabular}

$\mathrm{ML}$ velocity $(\mathrm{cm} / \mathrm{s})$

\begin{tabular}{c|c|c|c|c|c|c}
\hline EO & $1.2 \pm 0.21$ & $1.1 \pm 0.19$ & & & \\
\cline { 1 - 3 } EC & $1.3 \pm 0.25$ & $1.2 \pm 0.28$ & 0.25 & $<0.001^{*}$ & 0.99 & $<0.001^{*}$ \\
\cline { 1 - 3 } ECF & $2.7 \pm 0.74$ & $2.5 \pm 1.5$ & & & \\
\hline RO & $1.2 \pm 0.18$ & $1.1 \pm 0.18$ & & & \\
\hline
\end{tabular}

COPD: chronic obstructive pulmonary disease; EO: eyes open; EC: eyes closed; ECF: eyes closed on foam rubber surface; RO: eyes open during respiratory overload; AP: anteroposterior; ML: mediolateral; data expressed as mean \pm standard deviation; ${ }^{*} p \leq 0.05$. 
Table 3 Correlations between balance performance under eyes closed on foam rubber surface (ECF) condition and functional capacity, peripheral muscle strength and respiratory muscle strength.

\begin{tabular}{|c|c|c|c|c|c|c|}
\hline \multirow{3}{*}{$\begin{array}{l}\text { Functional capacity, } \\
\text { peripheral muscle } \\
\text { strength and respiratory } \\
\text { muscle strength }\end{array}$} & \multicolumn{6}{|c|}{ Posturographic variables under ECF condition } \\
\hline & Area $\left(\mathrm{cm}^{2}\right)$ & $\begin{array}{l}\text { Total } \\
\text { displacement } \\
(\mathrm{cm})\end{array}$ & $\begin{array}{l}\text { AP standard } \\
\text { deviation } \\
\text { (cm) }\end{array}$ & $\begin{array}{l}\text { ML standard } \\
\text { deviation } \\
(\mathrm{cm})\end{array}$ & $\begin{array}{l}\text { AP velocity } \\
(\mathrm{cm} / \mathrm{s})\end{array}$ & $\begin{array}{c}\text { ML velocity } \\
(\mathrm{cm} / \mathrm{s})\end{array}$ \\
\hline & \multicolumn{6}{|c|}{ Pearson's correlations (p) } \\
\hline \multicolumn{7}{|l|}{ COPD $(n=14)$} \\
\hline GMWT (m) & $-0.09(0.76)$ & $-0.02(0.95)$ & $-0.41(0.17)$ & $0.42(0.13)$ & $-0.59(0.03)^{*}$ & $0.48(0.08)$ \\
\hline Glittre-ADL test (min) & $0.41(0.15)$ & $0.20(0.50)$ & $0.68(0.01)^{*}$ & $-0.18(0.55)$ & $0.67(0.009)^{*}$ & $-0.40(0.15)$ \\
\hline $\begin{array}{l}\text { DUL dynamometry } \\
\text { (kgf) }\end{array}$ & $0.02(0.93)$ & $-0.30(0.29)$ & $-0.02(0.95)$ & $0.09(0.75)$ & $-0.25(0.39)$ & $-0.09(0.76)$ \\
\hline $\operatorname{MIP}\left(\mathrm{cmH}_{2} \mathrm{O}\right)$ & $0.28(0.53)$ & $0.15(0.62)$ & $0.23(0.44)$ & $0.09(0.75)$ & $-0.01(0.97)$ & $0.13(0.66)$ \\
\hline $\operatorname{MEP}\left(\mathrm{cmH}_{2} \mathrm{O}\right)$ & $0.03(0.90)$ & $0.41(0.14)$ & $-0.14(0.65)$ & $0.28(0.32)$ & $-0.23(0.43)$ & $0.60(0.02)^{*}$ \\
\hline \multicolumn{7}{|l|}{ Without COPD ( $n=9)$} \\
\hline 6MWT (m) & $0.03(0.94)$ & $0.01(0.98)$ & $0.04(0.91)$ & $-0.22(0.57)$ & $-0.03(0.93)$ & $0.02(0.95)$ \\
\hline Glittre-ADL test (min) & $-0.01(0.98)$ & 0.03 (0.95) & $0.28(0.50)$ & $0.05(0.90)$ & $0.22(0.60)$ & $-0.05(0.90)$ \\
\hline $\begin{array}{l}\text { DUL dynamometry } \\
\text { (kgf) }\end{array}$ & $-0.08(0.88)$ & $0.02(0.98)$ & $0.05(0.93)$ & $-0.10(0.85)$ & $0.03(0.96)$ & $-0.20(0.70)$ \\
\hline $\mathrm{MIP}\left(\mathrm{cmH}_{2} \mathrm{O}\right)$ & $0.46(0.22)$ & $0.86(0.006)^{*}$ & $0.37(0.33)$ & $0.23(0.54)$ & $0.32(0.40)$ & $0.45(0.23)$ \\
\hline $\operatorname{MEP}\left(\mathrm{cmH}_{2} \mathrm{O}\right)$ & $-0.44(0.28)$ & $-0.09(0.85)$ & $0.33(0.43)$ & $-0.53(0.18)$ & $-0.32(0.44)$ & $-0.53(0.18)$ \\
\hline
\end{tabular}

COPD: chronic obstructive pulmonary disease; AP: anteroposterior; ML: mediolateral; 6MWT: Six-Minute Walk Test; ADL: activity of daily living; MIP: maximum inspiratory pressure; MEP: maximum expiratory pressure; DUL: dominant upper limb; * $\leq 0.05$.

found between a better performance Glittre-ADL test and better balance in AP standard deviation $(\mathrm{r}=0.68, \mathrm{p}=0.01)$ and $\mathrm{AP}$ velocity $(\mathrm{r}=0.67, \mathrm{p}=0.009)$. A positive correlation was found between greater maximum expiratory pressure and better balance in ML velocity $(\mathrm{r}=0.60, \mathrm{p}=0.02)$; and a negative correlation was found between a shorter distance on the 6MWT and better balance in AP velocity $(\mathrm{r}=-0.59$, $\mathrm{p}=0.03)$.

\section{DISCUSSION}

The main findings of the present study were:

- the older adults with COPD had altered balance demonstrated by greater total displacement, ML standard deviation and AP velocity;

- postural control during static balance was worse on an unstable surface (ECF) compared to other conditions;

- impaired balance in the AP direction was associated with poor functional and exercise capacity;
- impaired postural control in the ML direction was associated with greater expiratory muscle strength.

The older adults with COPD presented with worse postural control (increased total displacement, sway in the $\mathrm{ML}$ direction and velocity in the AP direction) compared to older adults without pulmonary disease. Smith et al. ${ }^{8}$ also reported balance deficits in both directions when postural perturbation during arm movements on the sagittal plane was performed in individuals with COPD. This balance deficit was in the same perturbation direction (AP). Moreover, concomitant deficit in the ML direction was found in individuals with severe COPD. In contrast, a previous study ${ }^{3}$ found no impaired balance in the AP direction, suggesting a possible compensation for perturbations in this direction by increased angular movements of the hip. Deficits in postural control are still found in individuals with COPD with similar physical performance as individuals without pulmonary disease. This underscores the need for specific assessments 
and balance interventions for patients in pulmonary rehabilitation programs.

In the analysis of the different balance conditions, eyes closed on an unstable surface (foam) was more challenging in comparison to other diseases, but with no differences in the group interaction. Thus, it is suggested that unstable surfaces lead to greater difficulty maintaining postural control in physically active older adults with or without respiratory disease. These results are similar to those reported by Pedrozo and Silveira, ${ }^{25}$ who found no differences in balance tasks involving the somatosensory system in individuals with COPD compared to the group without COPD. Conversely, Janssens et al..$^{7}$ and Oliveira et al. ${ }^{26}$ found changes in postural control on an unstable surface in individuals with stable COPD compared to healthy individuals. Thus, one cannot discard the possibility that somatosensory impairment exerts an influence on balance deficits in this population.

Although an increase in respiratory demand can disturb balance due to increased trunk muscle activity, ${ }^{8,27}$ no balance deficit was found in the present study during increased respiratory load in comparison to the other balance tasks or in the group interaction analysis. This lack of balance impairment during increased respiratory load may be explained by the shorter exposure time to the condition (1 minute) compared to the time employed in the study conducted by Janssens et al. (7 minutes). ${ }^{28}$ Moreover, the fact that the older adults with COPD participated in a pulmonary rehabilitation program and had respiratory muscle strength close to the predicted value may have impeded the influence of increased respiratory load on the maintenance of postural control.

There was a correlation between a limited performance on the 6MWT among the older adults with COPD and a worse balance in the AP direction on the unstable surface. Liwsrisakun et al. ${ }^{29}$ demonstrated that a distance of $<300$ meters traveled on the 6MWT is an important risk factor for impaired balance in individuals with COPD. This assumption is supported by Castro et al., ${ }^{4}$ who found a correlation between a shorter distance travelled on the 6MWT and impaired functional balance measured using the Timed Up and Go Test.

A correlation was also found between the worse balance in the AP direction and worse performance on the GlittreADL test, suggesting that balance deficit limits activities of daily living in older adults with COPD. In contrast, no correlation was found between peripheral muscle strength and balance, which differs from results described by Beauchamp et al. ${ }^{30}$ The fact that the individuals with COPD participated in a pulmonary rehabilitation program involving resistance exercises for the upper and lower limbs may have reduced the balance deficit expected for this population. An interesting finding was the correlation between greater expiratory muscle strength in the older adults with COPD and worse balance in the ML direction on the unstable surface. This suggests that preserved expiratory muscle strength does not exert a significant influence on the postural control of these individuals on unstable surfaces and that other underlying mechanisms may be determinants of these deficits.

The present study has limitations that should be considered. First, the results are merely speculative, since they were based on a small sample, not enabling stratification of the analysis by COPD severity level. Prospective studies with larger sample sizes are needed to confirm these findings. Second, the cross-sectional design does not enable the identification of the causal factors of altered balance in older adults with moderate to very severe COPD. Third, it was not possible to recruit a sample of older adults with COPD before pulmonary rehabilitation enrollment. The fact that our sample with COPD had participated in a pulmonary rehabilitation program may have underestimated the postural control deficits observed in this patient population. However, a comparative group of physically active older adults was chosen to allow an appropriate comparison. This study can broaden knowledge on postural control strategies in the population of older adults with COPD who are physically active and participate in a pulmonary rehabilitation program. Fourth, we only investigated the influence of motor responses and respiratory mechanics on balance. Postural control is a complex process that involves different systems. Thus, various measures, such as the recording of sensory components and muscle reaction activity, could be useful for a better understanding of postural control in older adults with COPD. Also, although posturography has a high sensitivity for the assessment of balance, clinical scales involving functional activities may broaden the analysis of balance in this population.

\section{CONCLUSION}

In the present study, older adults with COPD who participated in a pulmonary rehabilitation program exhibited a less efficient postural control strategy than physically active older adults without pulmonary disease. The unstable surface task caused greater perturbation to balance compared to increased load on the respiratory muscles. Impaired postural control in older adults with COPD is associated with functional and exercise capacity. These findings can assist in the understanding of postural control in individuals with COPD who participate in a pulmonary rehabilitation program. 


\section{ACKNOWLEDGMENTS}

The authors are grateful to the Human Motricity Laboratory for making available the posturographic equipment and the training of the researchers. The authors also thank the volunteers who agreed to participate in the study.

\section{CONFLICT OF INTERESTS}

The authors declare no conflict of interest.

\section{FUNDING}

None.

\section{REFERENCES}

1. Global Initiative for Chronic Obstructive Lung Disease. Global Strategy for the Diagnosis, Management, and Prevention of Chronic Obstructive Pulmonary Disease [Internet]. Global Initiative for Chronic Obstructive Lung Disease; 2019 [Accessed in Sept 10, 2019]. Available at: https:// goldcopd.org/wp-content/uploads/2018/11/GOLD-2019-v1.7-FINAL14Nov2018-WMS.pdf

2. Jaitovich A, Barreiro E. Skeletal Muscle Dysfunction in Chronic Obstructive Pulmonary Disease. What We Know and Can Do for Our Patients. Am J Respir Crit Care Med. 2018;198(2):175-86. https://doi.org/10.1164/ rccm.201710-2140Cl

3. Yentes JM, Rennard SI, Schmid KK, Blanke D, Stergiou N. Patients with Chronic Obstructive Pulmonary Disease Walk with Altered Step Time and Step Width Variability as Compared with Healthy Control Subjects. Ann Am Thorac Soc. 2017;14(6):858-66. https://doi.org/10.1513/ AnnalsATS.201607-5470C

4. Castro LA, Ribeiro LR, Mesquita R, de Carvalho DR, Felcar JM, Merli MF, et al. Static and Functional Balance in Individuals With COPD: Comparison With Healthy Controls and Differences According to Sex and Disease Severity. Respir Care. 2016;61(11):1488-96. https://doi. org/10.4187/respcare.04749

5. Oliveira CC, Lee AL, McGinley J, Thompson M, Irving LB, Anderson $\mathrm{GP}$, et al. Falls by individuals with chronic obstructive pulmonary disease: a preliminary 12-month prospective cohort study. Respirology. 2015;20(7):1096-101. https://doi.org/10.1111/resp.12600

6. Forbes PA, Chen A, Blouin JS. Sensorimotor control of standing balance. Handb Clin Neurol. 2018;159:61-83. https://doi.org/10.1016/B9780-444-63916-5.00004-5

7. Janssens L, Brumagne S, McConnell AK, Claeys K, Pijnenburg M, Burtin C, et al. Proprioceptive Changes Impair Balance Control in Individuals with Chronic Obstructive Pulmonary Disease. PLoS One. 2013;8(3):e57949. https://doi.org/10.1371/journal. pone.0057949

8. Smith MD, Chang AT, Hodges PW. Balance recovery is compromised and trunk muscle activity is increased in chronic obstructive pulmonary disease. Gait Posture. 2016;43:101-7. https://doi.org/10.1016/j. gaitpost.2015.09.004

9. Spruit MA, Singh SJ, Garvey C, ZuWallack R, Nici L, Rochester C, et al. An official American thoracic society/European respiratory society statement: Key concepts and advances in pulmonary rehabilitation. Am J Respir Crit Care Med. 2013;188(8):e13-64. https://doi.org/10.1164/ rccm.201309-1634ST

10. Vandenbroucke JP, von Elm E, Altman DG, Gøtzsche PC, Mulrow CD, Pocock SJ, et al. Strengthening the Reporting of Observational Studies in Epidemiology (STROBE): explanation and elaboration. Epidemiology. 2007;18(6):805-35. https://doi.org/10.1097/EDE.0b013e3181577511

11. O'Shea SD, Taylor NF, Paratz JD. Measuring muscle strength for people with chronic obstructive pulmonary disease: retest reliability of hand-held dynamometry. Arch Phys Med Rehabil. 2007;88(1):32-6. https://doi.org/10.1016/j.apmr.2006.10.002

12. Pereira CAC. Espirometria. J Bras Pneumol [Internet]. 2002 [Accessed in Jun 14, 2019];28(Suppl. 3):S1-81. Available at: http://www. saude.ufpr.br/portal/labsim/wp-content/uploads/sites/23/2016/07/ Suple_139_45_11-Espirometria.pdf
13. Souza R. Pressões respiratória estáticas máximas. J Bras Pneumol [Internet] 2002 [Accessed in Jun 14, 2019];28(Suppl. 3):S155-65. Available at: http:// www.scielo.br/scielo.php?script=sci_nlinks\&ref=000092\&pid=S1413 3555200700050000600005\&lng=en

14. Costa D, Gonçalves HA, de Lima LP, Ike D, Cancelliero KM, Montebelo MIL. New reference values for maximal respiratory pressures in the Brazilian population. J Bras Pneumol. 2010;36(3):306-12. https://doi. org/10.1590/S1806-37132010000300007

15. Kovelis D, Segretti NO, Probst VS, Lareau ZC, Brunetto AF, Pitta F. Validation of the modified pulmonary functional status and dyspnea questionnaire and the medical research council scale for use in Brazilian patients with chronic obstructive pulmonary disease. J Bras Pneumol. 2008;34(12):100818. http://dx.doi.org/10.1590/S1806-37132008001200005

16. Winter DA, Patla AE, Frank JS. Assessment of balance control in humans. Med Prog Technol [Internet]. 1990 [Accessed in Jun 14, 2019];16(1-2):31-51. Available at: https:/www.ncbi.nlm.nih.gov/ pubmed/2138696

17. Palmieri RM, Ingersoll CD, Stone MB, Krause BA. Center-of-Pressure Parameters Used in the Assessment of Postural Control. J Sport Rehabil. 2002;11(1):51-66. https://doi.org/10.1123/jsr.11.1.51

18. Harro CC, Garascia C. Reliability and Validity of Computerized force platform measures of balance function in healthy older adults. J Geriatr Phys Ther. 2019;42(3):E57-E66. http://dx.doi.org/10.1519/JPT.0000000000000175

19. Howcroft J, Lemaire ED, Kofman J, Mcllroy WE. Elderly fall risk prediction using static posturography. PLoS One. 2017;12(2):e0172398. https:// doi.org/10.1371/journal.pone.0172398

20. Holland AE, Spruit MA, Troosters T, Puhan MA, Pepin V, Saey D, et al. An official European Respiratory Society/American Thoracic Society technical standard: field walking tests in chronic respiratory disease. Eur Respir J. 2014;44:1428-46. https://doi.org/10.1183/09031936.00150314

21. Singh SJ, Puhan MA, Andrianopoulos V, Hernandes NA, Mitchell KE, Hill CJ, et al. An official systematic review of the European Respiratory Society/American Thoracic Society: measurement properties of field walking tests in chronic respiratory disease. Eur Respir J. 2014;44:144778. https://doi.org/10.1183/09031936.00150414

22. Iwama AM, Andrade GN, Shima P, Tanni SE, Godoy I, Dourado VZ. The six-minute walk test and body weight-walk distance product in healthy Brazilian subjects. Braz J Med Biol Res. 2009;42(11):1080-5. https://doi.org/10.1590/S0100-879X2009005000032

23. Skumlien S, Hagelund T, Bjørtuft Ø, Ryg MS. A field test of functional status as performance of activities of daily living in COPD patients. Respir Med. 2006;100(2):316-23. https://doi.org/10.1016/j.rmed.2005.04.022

24. Reis CM, Karloh M, Fonseca FR, Biscaro RRM, Mazo GZ, Mayer AF. Functional capacity measurement: reference equations for the Glittre Activities of Daily Living test. J Bras Pneumol. 2018;44(5):370-7. https://doi.org/10.1590/S1806-37562017000000118

25. Pedrozo MD, Silveira AF. Balance assessment in people with chronic obstructive pulmonary disease. Fisioter Mov. 2015;28(1):149-56. https://doi.org/10.1590/0103-5150.028.001.A015

26. Oliveira CC, Lee AL, McGinley J, Anderson GP, Clark RA, Thompson M, et al. Balance and Falls in Acute Exacerbation of Chronic Obstructive Pulmonary Disease: A Prospective Study. COPD. 2017;14(5):518-25. http://dx.doi.org/10.1080/15412555.2017.1342232 
27. Kuznetsov NA, Riley MA. Effects of Breathing on Multijoint Control of Center of Mass Position During Upright Stance. J Mot Behav. 2012;44(4):241-53. https://doi.org/10.1080/00222895.2012.6 88894

28. Janssens L, Pijnenburg M, Claeys K, McConnell AK, Troosters T, Brumagne S. Postural strategy and back muscle oxygenation during inspiratory muscle loading. Med Sci Sports Exerc. 2013;45(7):1355-62. https:// doi.org/10.1249/MSS.0b013e3182853d27
29. Liwsrisakun C, Pothirat C, Chaiwong W, Bumroongkit C, Deesomchok A, Theerakittikul T, et al. Exercise Performance as a Predictor for Balance Impairment in COPD Patients. Medicina. 2019;55(5):171. https://doi. org/10.3390/medicina55050171

30. Beauchamp MK, Sibley KM, Lakhani B, Romano J, Mathur S, Goldstein RS, et al. Impairments in Systems Underlying Control of Balance in COPD. Chest. 2012;141(6):1496-503. https://doi.org/10.1378/ chest.11-1708 